\title{
Pluronic mixed micelles overcoming methotrexate multidrug resistance: in vitro and in vivo evaluation
}

This article was published in the following Dove Press journal:

International Journal of Nanomedicine

15 April 2013

Number of times this article has been viewed

\section{Yanzuo Chen' \\ Xianyi Sha' \\ Wei Zhang ${ }^{1,2}$ \\ Weitong Zhong' \\ Zhuoyang Fan' \\ Qiuyue Ren' \\ Liangcen Chen' \\ Xiaoling Fang'}

'Key Laboratory of Smart Drug Delivery, Ministry of Education and PLA, Department of Pharmaceutics, School of Pharmacy, Fudan University, Shanghai, People's Republic of China ${ }^{2}$ Department of Pharmaceutical Sciences, School of Pharmacy, University of Pittsburgh, Pittsburgh, PA, USA
Correspondence: Xiaoling Fang Key Laboratory of Smart Drug Delivery, Ministry of Education and PLA, Department of Pharmaceutics, School of Pharmacy, Fudan University, Lane 826 Zhangheng Road, Shanghai 201203, People's Republic of China

Tel +86 2I 5198007 I

Fax +86 21 51980072

Email xlfang@shmu.edu.cn
Abstract: A Pluronic polymeric mixed micelle delivery system was developed in this study by using Pluronic P105 and F127 block copolymers to encapsulate the antitumor compound, methotrexate (MTX). The MTX-loaded Pluronic P105/F127 mixed micelle exhibited the spherical shape with about $22 \mathrm{~nm}$ in diameter, high encapsulation efficiency (about $85 \%$ ) and $\mathrm{pH}-$ dependent in vitro drug release. In this study, A-549 and $\mathrm{KBv}$ cell lines were selected as multidrug resistance tumor cell models, while $\mathrm{H}-460$ and $\mathrm{KB}$ cell lines were chosen as sensitive tumor cells. The MTX-loaded Pluronic P105/F127 mixed micelle exhibited significant higher in vitro cytotoxicity in multidrug resistant tumor cells than that of control (MTX injection) mainly because of higher cellular uptake of MTX. The pharmacokinetic studies indicated that the Pluronic micelles significantly prolonged systemic circulation time of MTX compared to MTX injection. Moreover, a much stronger antitumor efficacy in KBv tumor xenografts nude mice was observed in the MTX-loaded Pluronic P105/F127 mixed micelle group, than MTX. Collectively, Pluronic P105/F127 mixed micelles could significantly enhance the antitumor activity of MTX and might be a promising drug delivery platform for multidrug resistance modulation.

Keywords: multidrug resistance, drug delivery system, micelles, Pluronic, methotrexate

\section{Introduction}

Methotrexate (MTX) is a folate antimetabolite, which can effectively deactivate the metabolism of diseased cells through programmed cell death, apoptosis, and it has been used extensively in the treatment of various malignancies including childhood acute lymphocytic leukemia, osteosarcoma, non-Hodgkin's lymphoma, Hodgkin's disease, head and neck cancer, lung cancer, and breast cancer. ${ }^{1,2}$ MTX can cease intracellular folate metabolism and finally blocks the synthesis of thymine and purines, leading to impairment of tumor growth and induction of cell death by secondary genotoxic effects or apoptosis. ${ }^{3}$ Unfortunately, the drug resistance in certain cancer cells significantly restricts the effectiveness of MTX in clinic. Multidrug resistance (MDR) in cancer is a major cause for the failure of chemotherapy in the treatment of cancer patients. A major mechanism for the occurrence of MDR often results from elevated expression of particular proteins, such as glycoprotein $\mathrm{P}$ (P-gp), which can result in an increased efflux of the cytotoxic drugs from the cancer cells, thus lowering their intracellular concentrations. In certain cases, up to 100-fold overexpression of P-gp in MDR cancerous cells has been observed. ${ }^{4}$ Other resistance proteins, such as lung resistance protein and MDRassociated protein (MRP), have been reported to be simultaneously involved in MDR tumors, ${ }^{5}$ which significantly limit the clinical application of MTX. ${ }^{6}$ 
In order to overcome MDR, several formulation strategies have been proposed, including liposomes, nanocapsules and nanoparticles, ${ }^{7-11}$ polymer-drug conjugates, ${ }^{12,13}$ and polymeric micelles, ${ }^{14,15}$ by either delivery of drug resistance modulators (P-gp substrates), agents that regulate intracellular $\mathrm{pH}$ or lower the apoptotic threshold, or in combination with energy delivery to enhance the effectiveness of anticancer agents in refractory tumors. ${ }^{16}$ As a promising nanotechnology, anticancer drug-loaded polymeric micelles have been evaluated in several clinical trials. ${ }^{17-20}$ Recently, it has been reported that selecting proper polymer materials can implement more than one inert carrier function by being biological response modifiers. ${ }^{21}$ It was found that some Pluronic block copolymers can be used as biological response modifiers that can inhibit the P-gp efflux system by adenosine triphosphate (ATP) depletion in MDR cancerous cells, resulting in drastic sensitization of these tumors to anticancer agents. ${ }^{22}$ Our group has recently reported that Pluronic polymeric micelle systems can enhance the cytotoxicity of anticancer drugs against MDR tumor cells, ${ }^{23,24}$ and increase cellular accumulation of Rhodamine-123 (a well known P-gp substrate) in human lung adenocarcinoma A-549 cells. ${ }^{25}$

However, the drug-loading characteristics and stability issues of mono-polymer micelles still need to be improved using mixed micelle formulation. ${ }^{25-27}$ Pluronic block copolymer is a representative of amphiphilic synthetic polymers which contain hydrophilic poly(ethylene oxide) (PEO) blocks and hydrophobic poly(propylene oxide) (PPO) blocks arranged in the triblock structure: PEO-PPO-PEO. Pluronics are subdivided into four categories based on the lipophilicity: hydrophilic copolymers (hydrophilic-lipophicbalance (HLB) $>20$ ) (I); lipophilic copolymers (HLB < 20) with intermediate length of PPO block ranging from 30 to 60 PO repeating units (II); and lipophilic copolymers (HLB < 20) with shorter (III a) and with longer PO blocks (III b). Group II Pluronic block copolymers have been reported to have the maximal inhibitory effects on P-gp efflux. ${ }^{28}$ Pluronic P105 block copolymer was a $\mathrm{PEO}_{37}-\mathrm{PPO}_{56}-\mathrm{PEO}_{37}$ triblock copolymer with molecular weight of $6500 \mathrm{Da}$, which belongs to the group II of Pluronic. It has been reported that it not only can encapsulate hydrophobic drugs but also can be used as MDR modulator in cancer therapy. ${ }^{29}$ Another important Pluronic block copolymer, Pluronic F127 (group I) has been reported to be applied extensively in various drug delivery systems due to its long PEO repulsive property. It is easy to observe that the length of hydrophobic moieties of P105 (PPO: 56) and F127 (PPO: 64) are very close. Pluronics with similar PPO moieties show cooperative aggregation and those with different PPO moieties show non-cooperative binding. ${ }^{30}$ Thus, Pluronic P105 and F127 were chosen as the micelle forming polymers in order to combine the advantages of these two block copolymers. In this study, MTX-loaded Pluronic P105/F127 mixed micelles (PF-MTX) were prepared using a thin-film hydration method. We attempted to conduct a systematic in vitro and in vivo evaluation of PF-MTX by performing in vitro cytotoxicity and cellular uptake in the sensitive and MDR tumor cells; biodistribution studies using fluorescein-labeled polymeric mixed micelles; and antitumor activity pharmacological effect in a KBv xenograft tumor nude mice model.

\section{Materials and methods Materials}

MTX was obtained from Zibo Panxin Pharm and Chemical Co, Ltd (Zibo, People's Republic of China). MTX stock solution was prepared by dissolving the injection product in $100 \mathrm{~mL}$ volumetric flask with deionized water. Pluronic P105 and F127 were kindly supplied by BASF Ltd (Shanghai, People's Republic of China). Purified deionized water was prepared using the Milli-Q plus system (EMD Millipore Co, Billerica, MA, USA). 3-(4, 5-dimethyl-thiazol-2-yl)-2, 5-diphenyl-tetrazolium bromide (MTT) was purchased from Sigma (St Louis, MO, USA). A bicinchoninic acid (BCA) protein assay kit was purchased from Beyotime Biotech Co, Ltd (Nantong, People's Republic of China). Dioctadecyl-3, 3, 3', 3'-tetramethylindotricarbocyanine iodide (DIR) was purchased from Biotium (Life Technologies, Carlsbad, CA, USA).

The human carcinoma KB, human embryonic kidney cell line (HEK)-293, human lung adenocarcinoma A-549, and human lung carcinoma $\mathrm{H}-460$ cell lines were purchased from Chinese Academy of Sciences Cells Bank (Shanghai, People's Republic of China). The MDR KBv cell line was obtained from Nanjing KeyGen Biotech Co, Ltd (Nanjing, People's Republic of China). Cell culture plates and dishes were obtained from Corning Inc (Corning, NY, USA). The cells were cultured in Roswell Park Memorial Institute (RPMI) 1640 medium, supplemented with $10 \%$ fetal bovine serum (FBS), $100 \mathrm{IU} / \mathrm{mL}$ penicillin and $0.1 \mathrm{mg} / \mathrm{mL}$ streptomycin solution at $37^{\circ} \mathrm{C}$ under $5 \% \mathrm{CO}_{2}$. All experiments were performed on cells in the logarithmic phase of growth.

Male Sprague Dawley rats $(200 \pm 20 \mathrm{~g})$ and BALB/c nude mice ( $20 \pm 2 \mathrm{~g}$ ), supplied by the Department of Experimental Animals, Fudan University (Shanghai, People's Republic of China), were acclimated at $25^{\circ} \mathrm{C}$ and $55 \%$ of humidity under natural light/dark conditions for 1 week before experiment. All animal experiments were carried out in accordance with 
guidelines evaluated and approved by the ethics committee of Fudan University (\#2012-7).

\section{Preparation of Pluronic polymeric mixed micelles}

The thin-film hydration method was applied to prepare the PF-MTX. ${ }^{25}$ Briefly, a thin polymeric film was formed in a round-bottom flask by removing the organic solvents from the mixed solution containing 1-50 mg of MTX, $1-100 \mu \mathrm{L}$ of triethylamine (TEA) and $300 \mathrm{mg}$ Pluronic mixture composed of Pluronic P105 and F127 with different ratios dissolved in $5 \mathrm{~mL}$ methanol by rotary evaporation. The thin-film was further dried under vacuum overnight at room temperature to remove any traces of remaining solvents. Then, the dry polymeric film was hydrated with $5 \mathrm{~mL}$ of water. The mixture was stirred at $750 \mathrm{rpm}$ for 45 minutes to obtain a micelle solution which was then filtrated through $0.22 \mu \mathrm{m}$ filter membrane to remove the unincorporated drug aggregates. The blank Pluronic P105/ F127 mixed micelles were prepared using the same method as that of PF-MTX without addition of MTX. The preparation of fluorescein-labeled P105/F127 micelles was almost the same as that of PF-MTX micelles, except that $80 \mu \mathrm{L}$ DIR $(1 \mathrm{mg} / \mathrm{mL}$ stock solution in dichloromethane) was added into the methanol containing $300 \mathrm{mg}$ Pluronic mixture before removing the organic solvents. Then, the free DIR was removed via CL-4B column chromatography (Shanghai Hanhong Chemical Co, Ltd, Shanghai, People's Republic of China).

\section{Characterization of MTX-loaded mixed micelles}

Morphology, particle size, and surface charge

Morphological observation of PF-MTX was performed using transmission electron microscopy (Jeol JEM-1230; JEOL Ltd, Tokyo, Japan) and atomic force microscopy (Veeco Instruments Inc, Planeview, NY, USA). The samples were negatively stained with $1 \%$ phosphotungstic acid for transmission electron microscopy measurement. A drop of the micellar suspension was placed on a clean mica surface, air dried, and then observed by atomic force microscopy. The particle size and $\zeta$-potential of polymeric micelles were measured by dynamic light scattering technique with a zeta potential and particle sizer (Malvern, nanozs; Malvern Instruments Ltd, Worcestershire, UK).

\section{Drug-loading coefficient and encapsulation ratio}

The content of MTX in sample was determined via highperformance liquid chromatography (HPLC) on a system equipped with a LC-15C pump and a RF-20A Fluorescence detector (Shimadzu Co, Kyoto, Japan). The mobile phase consisted of methanol and $0.025 \mathrm{M}$ sodium dihydrogen phosphate buffer ( $\mathrm{pH} 5.41)(24: 76, \mathrm{v} / \mathrm{v})$ pumped at a flow rate of $1.0 \mathrm{~mL} /$ minute after extraction by mobile phase. The HPLC column $\left(5 \mu \mathrm{m} \mathrm{C}_{18}, 150 \mathrm{~mm} \times 4.6 \mathrm{~mm}\right.$; Gemini ${ }^{\circledR}$, Phenomenex Inc, Torrence, CA, USA) was used at room temperature. Sample injection volume was $20 \mu \mathrm{L}$ and the detection wavelength was set at $313 \mathrm{~nm}$. The HPLC method was calibrated with standard solutions with different concentrations ranging from $0.1-100 \mu \mathrm{g} / \mathrm{mL}$ of MTX dissolved in mobile phase $\left(\mathrm{R}^{2}=0.9996\right)$. The limit of quantification was $1.0 \mathrm{ng} / \mathrm{mL}$. The coefficients of variation were all within 3.0\%. Drugloading coefficient (DL\%) and encapsulation ratio (ER\%) were calculated using the following equations:

$$
\mathrm{DL} \%=\frac{\text { Weight of the drug in micelles }}{\text { Weight of the feeding polymer and drug }} \times 100 \%
$$

$$
\text { ER } \%=\frac{\text { Weight of the drug in micelles }}{\text { Weight of the feeding drug }} \times 100 \%
$$

\section{Physical status of MTX in polymeric mixed micelles} Five mg of MTX, freeze dried PF-MTX, or physical mixture sealed in standard aluminum pans with lids were measured by differential scanning calorimeter (DSC 204; NETZSCHGeratebau GmbH, Selb, Germany) under nitrogen atmosphere at a flow rate of $20 \mathrm{~mL} /$ minute. The temperature ramp speed was set $10^{\circ} \mathrm{C} /$ minute from $30^{\circ} \mathrm{C}$ to $180^{\circ} \mathrm{C}$. Indium was used as the standard reference to calibrate the temperature and energy scales of the instrument.

\section{Stability studies}

The optimal formulation of PF-MTX was lyophilized and stored at $4^{\circ} \mathrm{C}$ for 6 months to investigate its storage stability. The drug content and particle size were monitored at predetermined time points during the storage period.

\section{In vitro release of MTX-loaded micelles}

MTX in vitro release from PF-MTX was monitored using the dialysis method. One mL of PF-MTX solution (containing $0.1 \mathrm{mg}$ MTX) was introduced into a dialysis bag (molecular weigh cut off [MWCO] of $3500 \mathrm{Da}$; Greenbird Inc, Shanghai, People's Republic of China), and then the end sealed dialysis bag was submerged fully into $50 \mathrm{~mL}$ of phosphate buffered saline (PBS; pH 7.4) or acetate buffer (pH 5.0) at $37^{\circ} \mathrm{C}$ with stirring at $100 \mathrm{rpm}$ for 48 hours. At appropriate time intervals $(0,15,30$ minutes and $1,2,4,8,12,24$, 
48 hours), $0.2 \mathrm{~mL}$ aliquots were withdrawn and replaced with an equal volume of fresh medium. The concentration of MTX in samples was determined by HPLC as described above with correction for the volume replacement. MTX release from stock solution was also conducted under the same conditions as a control.

\section{In vitro anti-tumor efficacy of PF-MTX}

A-549, H-460, KB, and KBv cells were seeded in 96-well plates at the density of $5 \times 10^{3}$ cells per well. After a 24-hour incubation, the growth medium was replaced with $200 \mu \mathrm{L}$ medium containing corresponding drug samples (MTX and PF-MTX) with various concentrations. After a 72-hour incubation, cell survival was measured using tetrazolium salt MTT assay. Briefly, $180 \mu \mathrm{L}$ of fresh growth medium and $20 \mu \mathrm{L}$ of MTT $(5 \mathrm{mg} / \mathrm{mL})$ solution were added to each well. The plate was incubated for an additional 4 hours, and then $200 \mu \mathrm{L}$ dimethyl sulfoxide (DMSO) was added to dissolve the purple formazan crystals formed. The plates were vigorously shaken before measurement. The absorbance at $570 \mathrm{~nm}$ of each well was measured using a microplate reader (Tecan Safire ${ }^{2}$; Männedorf, Switzerland). KB, KBv, and HEK-293 cells were used to evaluate the toxicity of excipients. Cytotoxicity of Pluronic P105, F127, and blank P105/F127 micelles with various concentrations ranging from 0.1 to $1000 \mu \mathrm{g} / \mathrm{mL}$ was also conducted as described above.

\section{Cellular uptake}

The 24-well cell culture plates were seeded with $1 \times 10^{5}$ A-549, H-460, KB, or KBv cells per well and incubated at $37^{\circ} \mathrm{C}$ for 24 hours to allow the cell attachment. After a 24 -hour incubation, the medium was replaced by $0.5 \mu \mathrm{g} / \mathrm{mL}$ of MTX or PF-MTX solution in FBS-free RPMI 1640 medium. After a 4-hour incubation at $37^{\circ} \mathrm{C}$, cells were washed with cold PBS twice and then lysed with $0.4 \mathrm{~mL}$ PBS containing $1 \%$ Triton $\mathrm{X}-100$. After incubation, $100 \mu \mathrm{L}$ cell lysate was withdrawn and extracted with methanol $(200 \mu \mathrm{L} /$ sample $)$, and the mixture was then subjected to probe-type ultrasonic treatment (400 W, 10 cycles with 2 second active-3 second duration; JY92-IIN; SCIENTZ Biotech Co, Ltd, Ningbo, People's Republic of China) in ice bath for further MTX extraction. The extracts were centrifuged at $6000 \mathrm{rpm}$ for 6 minutes, and the supernatant was analyzed by HPLC as described above. The protein content in the sample was determined using the BCA protein assay kit in accordance with the method specified by the manufacturer. Cellular accumulation of MTX was normalized with respect to total protein content.

\section{In vivo pharmacokinetic studies}

Twelve Sprague Dawley rats were randomly divided into two groups for pharmacokinetic investigation. Group 1 and 2 received an intravenous administration of free MTX or PF-MTX through the tail vein at an equivalent dose of $4 \mathrm{mg} / \mathrm{kg}$ MTX versus the body weight. At predetermined time points of $0.083,0.25,0.5,1,2,4,8,12,24,48$, and 72 hours post injection, $0.2 \mathrm{~mL}$ of blood was collected into heparinized polyethylene tubes via the femoral artery and centrifuged at $1000 \mathrm{rpm}$ for 10 minutes to obtain plasma. The plasma was stored at $-70^{\circ} \mathrm{C}$ prior to HPLC analysis. Protein precipitation method was performed to process the plasma samples. Briefly, $80 \mu \mathrm{L}$ samples of plasma were mixed with $40 \mu \mathrm{L}$ perchloric acid and $25 \mu \mathrm{L}$ of $20 \mu \mathrm{g} / \mathrm{mL}$ ferulic acid methanol solution, which was used as the internal standard. The samples were vortexed for 3 minutes and then centrifuged at $10,000 \mathrm{rpm}$ for 10 minutes at $4^{\circ} \mathrm{C}$. Then $120 \mu \mathrm{L}$ supernatant was transferred to a clean tube and mixed with $10 \mu \mathrm{L}$ of $1 \mathrm{M}$ sodium hydroxide solution for HPLC analysis. BAPP 2.0 (Bioavailability program package 2.0, 2002; Nanging, People's Republic of China) was utilized to analyze the pharmacokinetic parameters. The Akaike's Information Criterion Rule was observed in the determination of the appropriate compartment model.

\section{Tissue distribution study}

In vivo real-time fluorescence imaging analysis was used to evaluate the biodistribution of P105/F127 mixed micelles. A tumor-bearing mice model was established by inoculating $0.2 \mathrm{~mL}$ PBS containing $5 \times 10^{6} \mathrm{KBv}$ cells into the right flank of nude mice. When the tumor volumes reached $0.8-1.0 \mathrm{~cm}^{3}$, the tumor-bearing mice were injected with $100 \mu \mathrm{L}$ DIRlabeled P105/F127 mixed micelles (DIR content: 0.2\%) through the tail vein. At predetermined time points, the mice were sacrificed and major organs were excised. The organ samples were rinsed with PBS ( $\mathrm{pH} 7.4)$ three times and then put into the board of fluorescence imaging system. Fluorescent images were captured using the Maestro ${ }^{\text {TM }}$ in vivo imaging system (excitation: 700-950 nm, emission: 780 nm long-pass; Cambridge Research and Instrumentation Inc, Woburn, MA, USA). The Maestro ${ }^{\text {TM }}$ (Cambridge Research and Instrumentation Inc) optical system consists of an optical head that includes a liquid crystal tunable filter, with a bandwidth of $20 \mathrm{~nm}$ and a scanning wavelength range of 500-950 $\mathrm{nm}$, with a custom designed, spectrally optimized lens system that relays the image to a scientificgrade megapixel charged couple device (CCD). The tunable filter was automatically stepped in $10 \mathrm{~nm}$ increments from 
700 to $950 \mathrm{~nm}$ while the camera captured images at each wavelength with constant 1 second exposure. The resulting images (spectral cube, containing a spectrum at every pixel) were loaded into Maestro ${ }^{\mathrm{TM}} 2.10$ (Cambridge Research and Instrumentation Inc) database and analyzed. The biodistribution of P105/F127 micelles was semiquantified by measuring the ratio of DIR fluorescence intensity recorded as total photons per centimeter squared and steradian per dissected organs.

\section{In vivo antitumor activity}

The antitumor efficacy of PF-MTX was evaluated in tumorbearing $\mathrm{BALB} / \mathrm{c}$ nude mice, which was established by inoculating $0.2 \mathrm{~mL}$ PBS containing $5 \times 10^{6} \mathrm{KBv}$ cells subcutaneously in the right flank of the mice. The first dose was scheduled 24 hours after the tumor implantation (designated as Day 0). Tumor-bearing mice were randomly divided into three groups and treated with $100 \mu \mathrm{L}$ of saline solution, MTX, or PF-MTX at a $5 \mathrm{mg} / \mathrm{kg}$ dose of MTX every four days for six continuous times. Individual body weight was monitored, and tumor volume (V) was calculated using the following formula:

$$
\mathrm{V}=\left(\mathrm{L} \times \mathrm{W}^{2}\right) / 2
$$

where length (L) is the longest diameter and width (W) is the shortest diameter perpendicular to length. At the end of the experiment, the animals were sacrificed by cervical dislocation and tumor masses were dissected and weighed. The liver and tumor tissues were fixed in 4\% paraformaldehyde solution for 48 hours and embedded in paraffin, sectioned at a thickness of $5 \mu \mathrm{m}$ and stained with hematoxylin and eosin (H\&E) for histopathological analysis under fluorescent microscope (Leica DMI 4000B; Leica Microsystems, Wetzlar, Germany).

\section{Data analysis}

Statistical analysis was performed by Student's $t$-test for two groups and one-way analysis of variance (ANOVA) for multiple groups. Data are expressed as means \pm standard deviation (SD). A $P$-value of less than 0.05 is considered statistically significant.

\section{Results and discussion \\ Formulation optimization of PF-MTX}

Drug encapsulation in Pluronic micelles was relatively low in comparison with other polymeric micelles. ${ }^{23}$ Thus, it is necessary to improve the MTX loading characteristics of P105/F127 mixed micelles by optimizing the formulation parameters. Pluronic P105 is a relatively hydrophobic Pluronic with long PPO chains and short PEO chains. It usually forms cylindrical aggregates in aqueous medium, which exhibit a higher solubilization capacity than spherical micelles formed by hydrophilic Pluronics. In contrast with P105, F127 has a well-known colloidal steric stabilization effect due to the high ratio of PEO to PPO. Hence, selection of the ratio of binary Pluronic block copolymers has to be considered carefully in order to further increase the drugloading capacity and stability of the polymeric micelles. In our study, the total amount of feeding Pluronic was kept at $300 \mathrm{mg}$ while the composition/ratio of Pluronic binary mixture was varied $(20 \mathrm{mg}$ MTX and $100 \mu \mathrm{L}$ TEA were added, which remained the same for this batch). The results showed that with the increasing P105 mass fraction from $0 \%$ to $100 \%$, DL $\%$ increased from $0.82 \%$ to $2.66 \%$, while the particle size of polymeric micelles only changed very slightly ranging from $27.44 \mathrm{~nm}$ to $20.24 \mathrm{~nm}$ (Figure 1A). Considering the MDR modulation capability of Pluronic P105, higher P105 mass fraction in the micellar formulation was necessary. Therefore, the P105 mass fraction was chosen as $88.89 \%$, and the resultant micelles had a small particle size of $21.46 \pm 2.33 \mathrm{~nm}$ with drug-loading coefficient of $2.65 \% \pm 0.24 \%$. DL \% and ER\% of Pluronic mixed micelles at different amounts of MTX feeding were also determined in Figure 1B. For optimization of the loading amount of MTX, P105 mass fraction was fixed at $88.89 \%$ and $100 \mu \mathrm{L}$ of TEA was added. We can see that with increasing the MTX feeding amount from $1 \mathrm{mg}$ to $50 \mathrm{mg}$, ER\% decreased gradually from $81.82 \%$ to $15.21 \%$. As shown in Figure $1 \mathrm{~B}$, when feeding at $10 \mathrm{mg}$ of MTX, the DL $\%$ could reach $2.83 \% \pm 0.47 \%$ along with encapsulation efficiency of $84.98 \% \pm 4.93 \%$. Thus, the amount of feeding MTX was chosen as $10 \mathrm{mg}$. It is known that MTX is hardly dissolvable in organic solvent without TEA. However, more TEA in the micellar formulation can cause the change in ionic strength and compatibility between the core of Pluronic micelles and drug molecules. ${ }^{31}$ Therefore, different amounts of TEA were exploited in order to further optimize the formulation. As presented in Figure 1C, DL\% of the micelles was found to be $2.70 \% \pm 0.16 \%$ with a particle size of $22.8 \pm 1.14 \mathrm{~nm}$ when $50 \mu \mathrm{L}$ TEA was added. Therefore, in the following study, the amount of TEA was fixed at $50 \mu \mathrm{L}$.

\section{Particles size, zeta potential, and morphology}

In order to achieve longevity during systemic circulation, the micelles must be small enough to evade detection and 

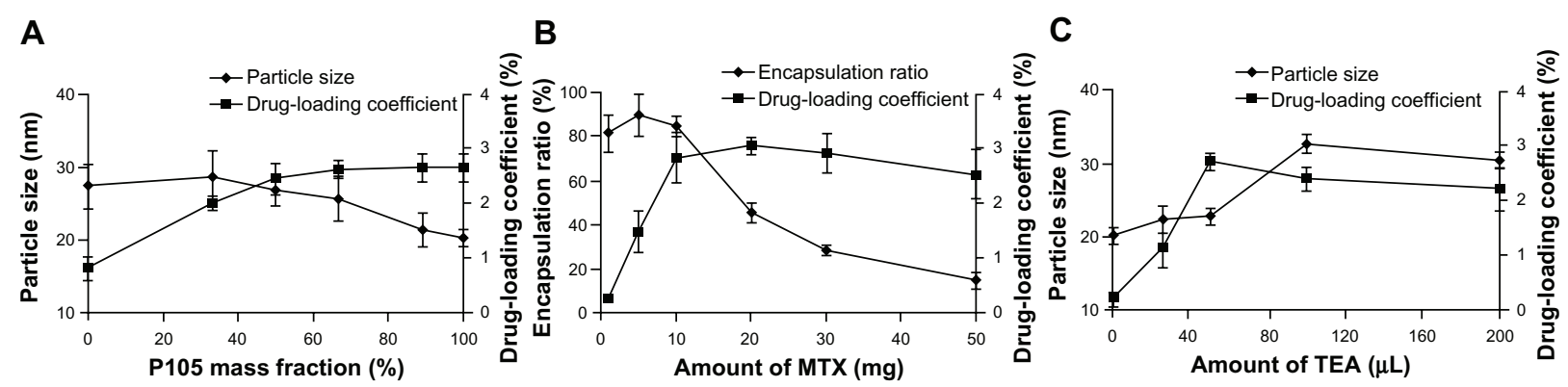

Figure I Particle size and drug-loading coefficient of mixed micelles with different PI05 mass fraction (A); drug-loading coefficient and encapsulation ratio of mixed micelles as a function of amount of MTX loading (B); particle size and drug-loading coefficient of mixed micelles as a function of TEA volume (C).

Note: Values are means \pm standard deviation $(n=3)$.

Abbreviations: MTX, methotrexate; TEA, triethylamine.

destruction by the reticuloendothelial system. ${ }^{25}$ The mean particle size of blank P105/F127 micelles was about $21.4 \mathrm{~nm}$, with a good polydispersity index between 0.10 and 0.14 . Polymeric micelles loaded with MTX did not visibly affect particle size and distribution (Table 1 and Figure $2 \mathrm{~A}$ ). The $\zeta$-potential value of blank P105/F127 micelles was $-4.23 \pm 1.12 \mathrm{mV}$, which was slightly higher than that of PF-MTX. Morphology of PFMTX was also observed by transmission electron microscopy and atomic force microscopy (Figure 2B and C). The image showed that PF-MTX was regularly spherical in shape. The dehydration and shrinkage of polymeric micelles during the sample process may lead to smaller diameters compared to the dynamic light scattering technique.

\section{Physical status of MTX in polymeric micelles}

The physical status of MTX encapsulated in polymeric matrix was investigated by differential scanning calorimeter analysis. As shown in Figure 3, both the MTX compound and the physical mixture of MTX and blank micelles exhibited endothermic melting peaks at around $167.3^{\circ} \mathrm{C}$. No corresponding endothermic peak was found in PF-MTX group, indicating that MTX existed as an amorphous state or a solid solution in the polymer matrix.

\section{In vitro stability study of PF-MTX}

As presented in Figure 4, 95.50\% of MTX remained in the polymeric micelles after 6-month storage, showing that the

Table I Particle size and $\zeta$-potential of the micelles

\begin{tabular}{llll}
\hline Formulation & Size $(\mathrm{nm})$ & Polydisperity & $\zeta$-potential $(\mathrm{mV})$ \\
\hline Blank mixed micelles & $21.4 \pm 1.30$ & $0.12 \pm 0.02$ & $-4.23 \pm 1.12$ \\
PF-MTX & $22.8 \pm 1.14$ & $0.17 \pm 0.04$ & $-2.44 \pm 0.59$ \\
\hline
\end{tabular}

Note: Values are means \pm standard deviation $(n=3)$.

Abbreviations: MTX, methotrexate; PF-MTX, methotrexate loaded PI05/FI27 mixed micelles. good storage stability of this formulation in the lyophilized form. The particle size of mixed micelles after reconstitution was slightly increased from $22.8 \mathrm{~nm}$ to $27.9 \mathrm{~nm}$, which might be due to the slight aggregation of hydrophobic micelle cores during the storage period.

\section{In vitro drug release}

The in vitro release profiles of MTX and PF-MTX are shown in Figure 5. The maximum concentration of MTX in the medium was about $2.0 \mu \mathrm{g} / \mathrm{mL}$, while the solubility of MTX in PBS (pH 7.4) and acetate buffer (pH 5.0) was about $40 \mu \mathrm{g} /$ $\mathrm{mL}$. Thus, a good sink condition was observed in this study. It was found that more than $95 \%$ of MTX was released within the first 2 hours at both $\mathrm{pH}$ conditions in the free MTX group, suggesting that MTX can diffuse through the dialysis membrane freely. As shown in Figure 5, more drug cumulative release from PF-MTX was found in $\mathrm{pH} 5.0$ acetate buffer, which was in good agreement with our previous studies. ${ }^{32}$ The charge repulsion between the micelles might improve the physical stability of PF-MTX, in the meantime, providing larger contacting area to the in vitro release medium that can facilitate the drug release from the micelles..$^{33}$ Additionally, the interaction between $\mathrm{H}^{+}$and $\mathrm{PEO}$ chain of Pluronic copolymers could make the PEO corona of polymeric micelles more extended. ${ }^{34}$ Therefore, more hydrophilic channels could form within the PEO shell which may speed up the MTX diffusion from the hydrophobic PPO core of PF-MTX. The results may suggest that after internalization into tumor cells, the low $\mathrm{pH}$ (around 5.0) in endolysosome might facilitate the release of MTX from polymeric micelles.

\section{In vitro cytotoxicity}

In vitro biocompatibility studies of Pluronic F127, P105 and blank P105/F127 micelles were carried out using KB, $\mathrm{KBv}$, and HEK-293 cell lines. HEK-293 was selected as 
A

Statistics graph

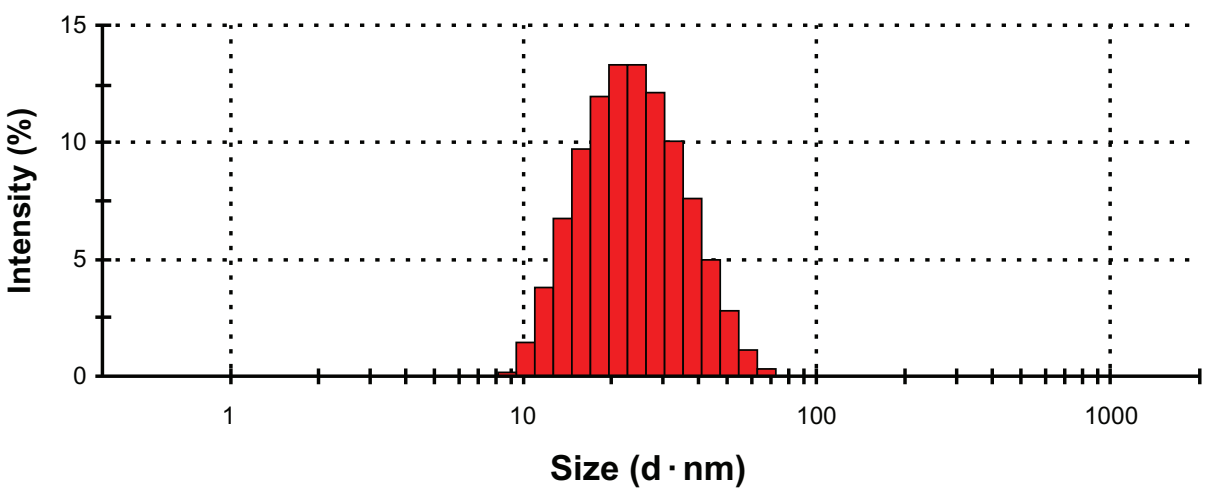

B

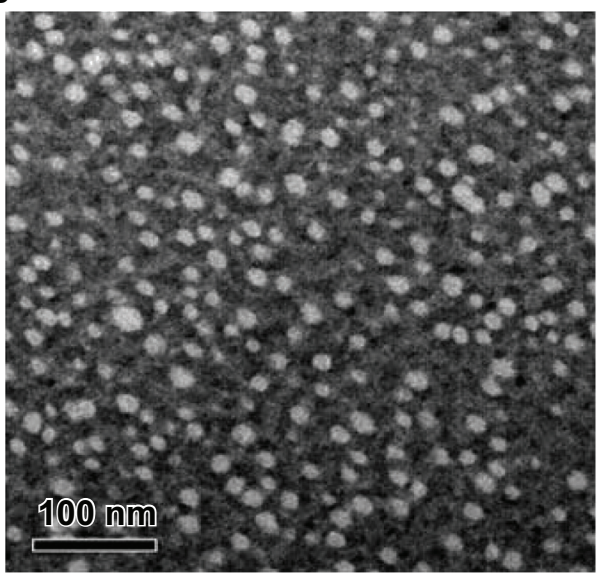

C

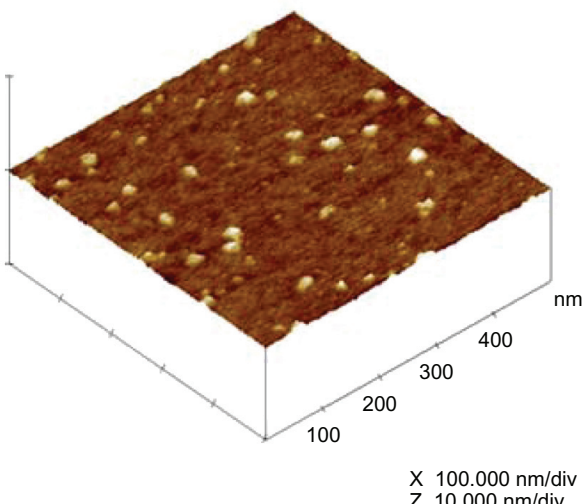

Figure 2 Particle size and size distribution of PF-MTX measured by dynamic light scattering (A); transmission electron microscopy image of PF-MTX, the bar is $100 \mathrm{~nm}$ (B); atomic force microscopy image of PF-MTX (C).

Abbreviation: PF-MTX, methotrexate loaded PI05/FI27 mixed micelles.

the human normal tissue cell model. In the concentration range $(0.1-1000 \mu \mathrm{g} / \mathrm{mL})$ used in this study, the cytotoxicity of Pluronic F127 and blank mixed micelles were negligible to $\mathrm{KB}$ and $\mathrm{KBv}$ cells. However, it was shown that Pluronic P105 displayed increasing cytotoxicity as the concentration increased, as shown in Figure 6A-C. As for HEK-293 cells, micelles displayed lower cytotoxic effect than those of Pluronic F127 and P105. The effect might be partly due to the cytostatic action of Pluronics micelles. Rapoport et al ${ }^{35}$ demonstrated that even a 48-hour incubation with Pluronic P105 micelles did not kill the A-2780 ovarian carcinoma cells but effectively prevented cell proliferation. Moreover,

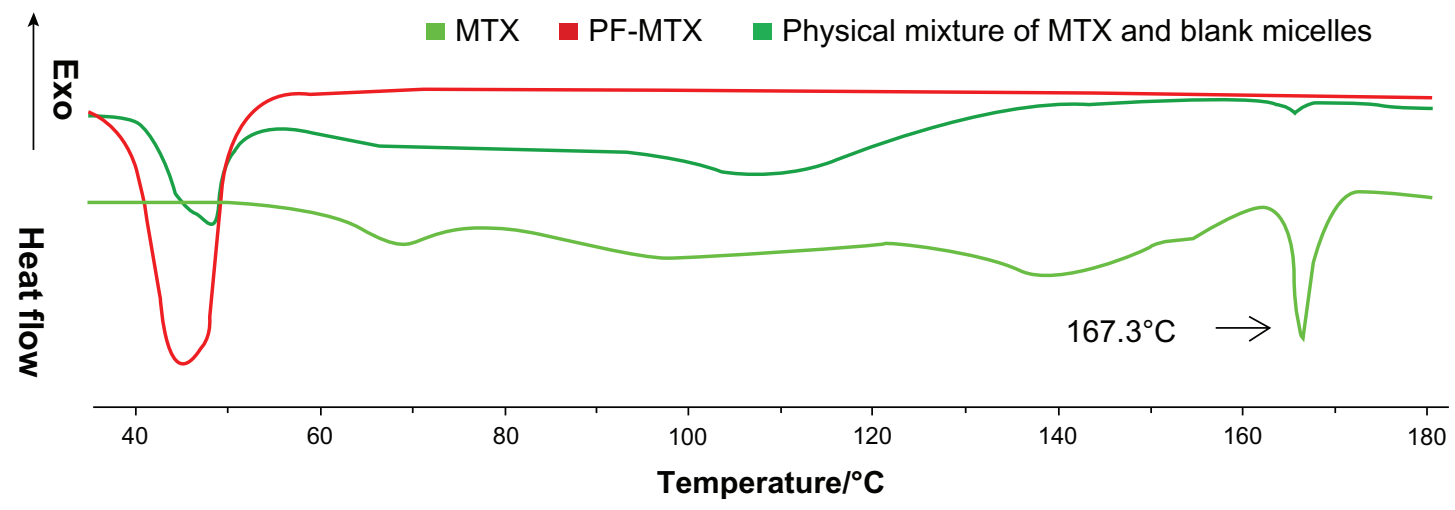

Figure 3 Differential scanning calorimetry thermograms of physical mixture of blank micelles and MTX, PF-MTX, and MTX. Abbreviations: MTX, methotrexate; PF-MTX, methotrexate loaded PI05/FI27 mixed micelles. 


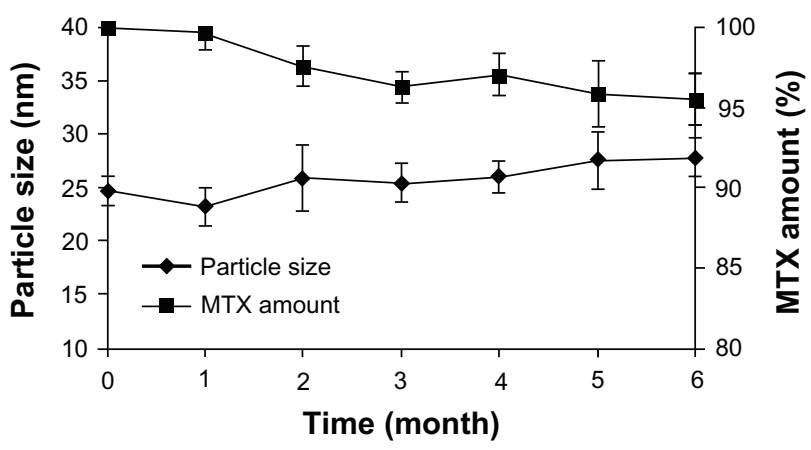

Figure 4 Particle sizes and MTX amounts of lyophilized mixed micelles kept at $4^{\circ} \mathrm{C}$ as a function of time.

Note: Values are means \pm standard deviation $(n=3)$.

Abbreviation: MTX, methotrexate.

the blank P105/F127 mixed micelle contained both F127 and P105 block copolymers. The lower toxicity in Figure 6C was also due to the lower polymer concentration of each component in blank mixed micelles compared to those of F127 and P105 alone groups. So P105/F127 mixed micelles had a better biocompatibility with normal tissue cells than Pluronic F127 or P105 for a single use. A-549 and KBv cell lines were selected as MDR tumor cell model $\mathrm{s}^{27}$ while $\mathrm{H}-460$ and $\mathrm{KB}$ cell lines were used as sensitive cell models ${ }^{36}$ in this study. After a 72-hour incubation with MTX or PF-MTX, the viability profiles of H-460 (Figure 7A), A-549 (Figure 7B), $\mathrm{KB}$ (Figure 7C), and KBv (Figure 7D) cells were determined. The obtained $\mathrm{IC}_{50}$ values for MTX and PF-MTX against these cell lines are shown in Table 2. It was found that PF-MTX exhibited much greater cytotoxicity than MTX in MDR cells $(P<0.01)$, with $\mathrm{IC}_{50}$ values decreased 3.81-fold for A-549 and 38.2-fold for $\mathrm{KBv}$ cells. As for sensitive cell lines, there is no big change in $\mathrm{IC}_{50}$ values between PF-PTX and free MTX. The slightly higher cytotoxicity of PF-MTX might be caused

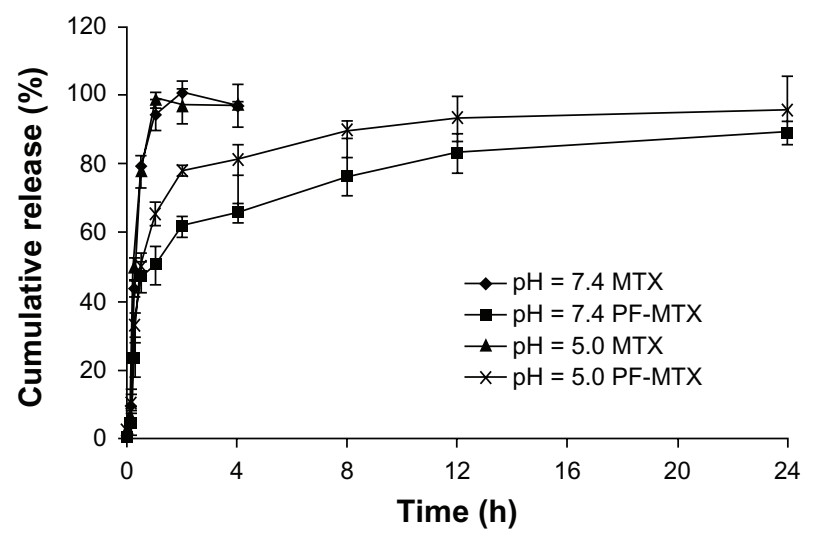

Figure 5 Release profiles of MTX from mixed micelles in PBS $(\mathrm{pH} 7.4)$ or acetate buffer $(\mathrm{pH} 5.0)$ medium at $37^{\circ} \mathrm{C}$.

Note: Values are means \pm standard deviation $(n=3)$.

Abbreviations: MTX, methotrexate; PBS, phosphate buffered saline. by the intrinsic biological activity of Pluronic block polymers although $\mathrm{H}-460$ and $\mathrm{KB}$ cells were not MDR cancerous cell lines. ${ }^{28}$ Thus, the results suggested that Pluronic may act as a chemosensitizer and potentiate cytotoxic effects of MTX in A-549 and KBv MDR cancer cells, partly due to the selective energy depleting effects of Pluronic copolymers, which was in good agreement with results reported previously. ${ }^{24,28}$

\section{Cellular uptake study}

To evaluate the effect of PF-MTX on MDR transporter mediated efflux, the accumulation of MTX was determined in A-549 and $\mathrm{KBv}$ cells. After incubation for 4 hours, the MTX cellular uptake of PF-MTX in A-549 and KBv MDR cells was much greater than for free MTX. On the contrary, for KB and H-460 sensitive cells, PF-MTX had similar MTX accumulation in cells compared to MTX (Figure 8), suggesting that P105/F127 block copolymers can effectively enhance MTX accumulation in MDR tumor cells. A high expression level of lung resistance protein was detected at the nuclear envelope and cytoplasm in A-549 cells, and it was investigated that lung resistance protein was involved in resistance to many drugs. Additionally, a number of ATP-binding cassette efflux pumps such as P-gp, MRP, and breast cancer resistance protein were also reported expressed in A-549 cells. ${ }^{37-39} \mathrm{It}$ has been reported that Pluronic unimers can incorporate into membranes followed by subsequent translocation into the cells and affecting various cellular functions, such as mitochondrial respiration, ATP synthesis, activity of drug efflux transporters, apoptotic signal transduction, and gene expression. ${ }^{21,40}$ Therefore, it is possible that the PF-MTX can result in modulation of drug resistance in MDR tumor cells. Furthermore, more MTX cellular accumulation of PF-MTX could be the reason for higher cytotoxicity against MDR cancer cells. Considering higher cytotoxicity and greater cellular uptake in $\mathrm{KBv}$ cells compared to A-549 cells in vitro, the KBv MDR tumor-bearing mice model was selected for further studies in vivo.

\section{Pharmacokinetic study}

The blood clearance curves for PF-MTX and MTX after intravenous administration to Sprague Dawley rats are shown in Figure 9. PF-MTX achieved much larger area under the curve (AUC) and longer half-life compared to free MTX, while free MTX was quickly removed from the circulation system. Compartmental analysis of the plasma concentrations showed a significant change in pharmacokinetic parameters of MTX in micelles compared to free MTX 
A

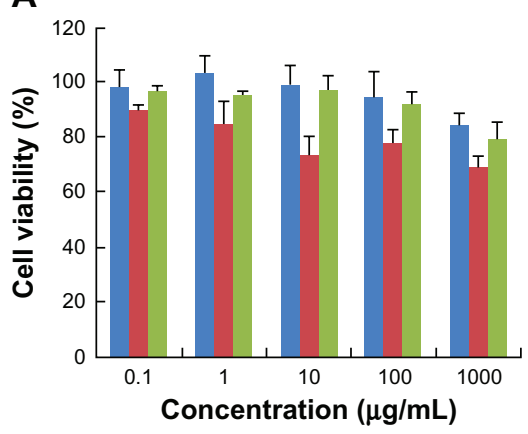

B

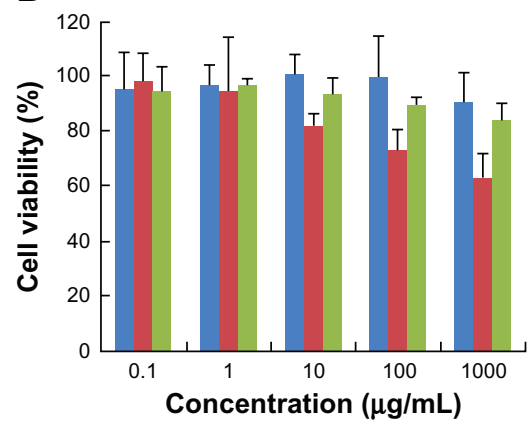

C

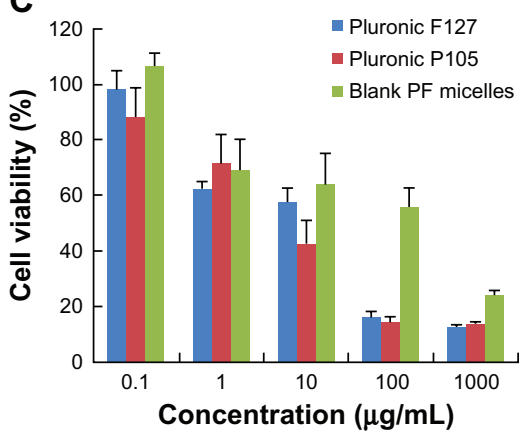

Figure 6 Cell viability of KB (A), KBv (B), and HEK-293 (C) cells as a function of varying concentrations of different excipients (Pluronic FI27, Pluronic PI05, or blank micelles) after 72 hours exposure.

Note: Values are means \pm standard deviation $(n=3)$.

(Table 3). It was also shown that PF-MTX could extend the elimination half-life $\left(\mathrm{t}_{1 / 2 \beta}\right)$ of MTX from 10.03 hours to 21.99 hours. Total body clearance of PF-MTX was significantly lower than MTX, implying a longer retention of the drug in blood circulation. In addition, the $\mathrm{AUC}_{0 \rightarrow \infty}$ of PF-MTX increased about 4.5-fold compared to that of MTX. The results indicated that PF-MTX had much longer systemic circulation time and much slower plasma elimi- nation rate than free MTX, which was in good agreement with our previous studies. ${ }^{24}$ This long blood circulation may be due to the long hydrophilic shell of mixed micelles formed by PEO segments of Pluronic block copolymer that can reduce the elimination rate of mononuclear phagocyte system uptake. ${ }^{14,41}$ Therefore, Pluronic polymeric mixed micelles could be used as a long-circulating drug delivery system for MDR cancer therapy.
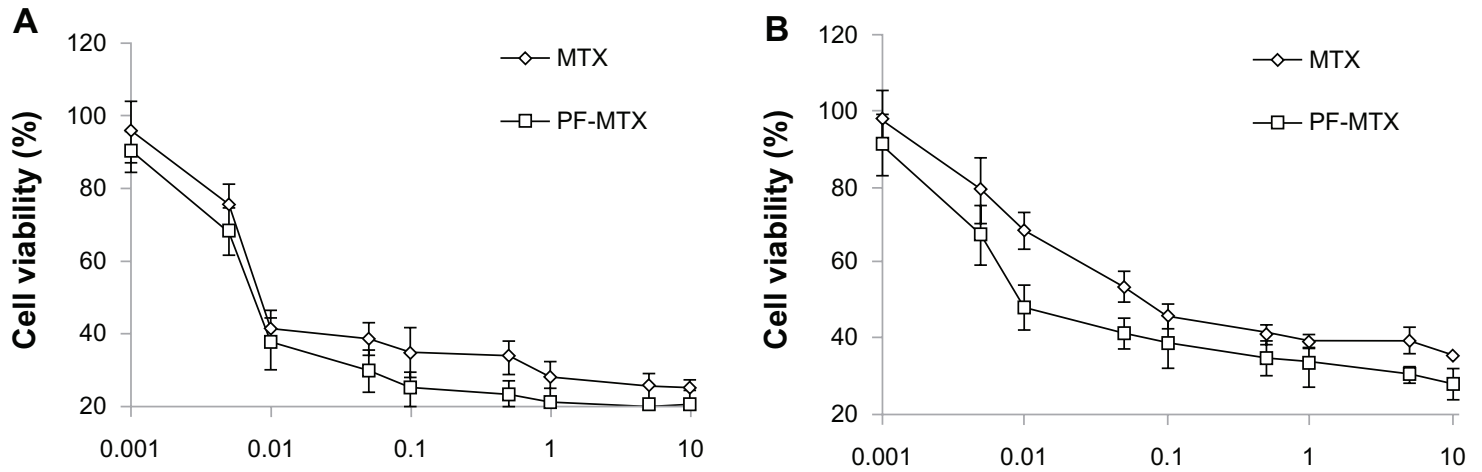

Concentration $(\mu \mathrm{g} / \mathrm{mL})$

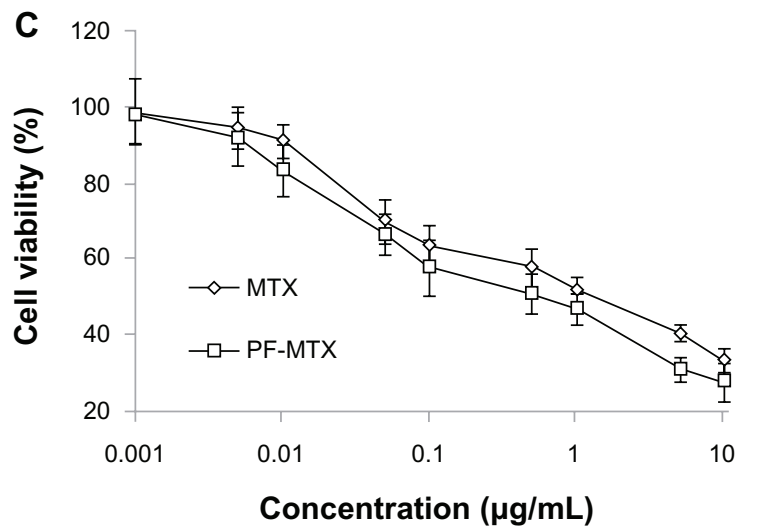

Concentration $(\mu \mathrm{g} / \mathrm{mL})$

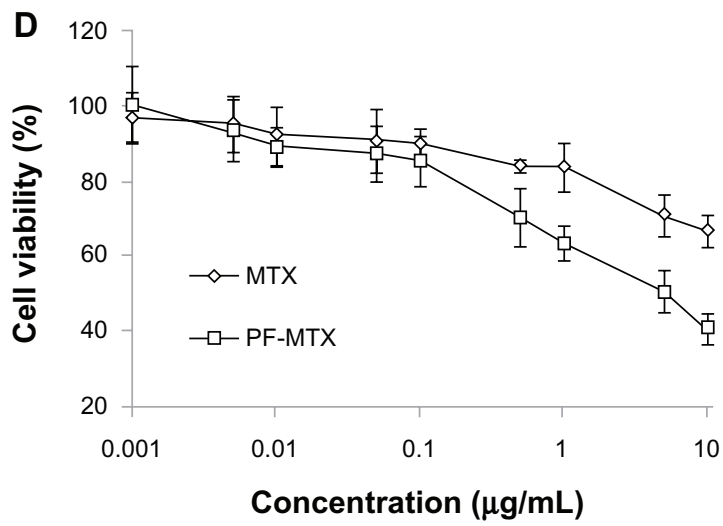

Figure 7 In vitro cytotoxicy of MTX and PF-MTX against H-460 (A), A-549 (B), KB (C), and KBv (D) cells at 72 hours.

Note: Values are means \pm standard deviation $(n=3)$.

Abbreviations: MTX, methotrexate; PF-MTX, methotrexate loaded PI05/FI27 mixed micelles. 
Table 2 Comparative $I_{50}$ values of MTX and PF-MTX on $\mathrm{H}-460$, $\mathrm{KB}, \mathrm{A}-549$, and $\mathrm{KBv}$ cell lines

\begin{tabular}{lcl}
\hline Cell lines & \multicolumn{1}{l}{ IC $_{50}$ values $(\mu \mathrm{g} / \mathrm{mL})$} & \\
\cline { 2 - 3 } & MTX & PF-MTX \\
\hline H-460 & $0.075 \pm 0.020$ & $0.024 \pm 0.009$ \\
KB & $0.85 I \pm 0.085$ & $0.502 \pm 0.179$ \\
A-549 & $0.274 \pm 0.023$ & $0.072 \pm 0.015^{* *}$ \\
KBv & $185.19 \pm 6.47$ & $4.850 \pm 0.662^{* *}$ \\
\hline
\end{tabular}

Notes: Values are means \pm standard deviation $(\mathrm{n}=3)$. **P $<0.01$, compared to the MTX treatment.

Abbreviations: MTX, methotrexate; PF-MTX, methotrexate loaded PI05/FI27 mixed micelles.

\section{Tissue distribution study}

Realtime near infrared (NIR) imaging system can be used to monitor the in vivo fate of Pluronic polymeric mixed micelles, and aid in the identification of key factors influencing biodistribution, pharmacokinetics and tumor accumulation of various drug carriers. ${ }^{42}$ At 1-hour post-injection, strong fluorescence intensities were observed in the liver, spleen, and lung, indicating that a large number of Pluronic micelles were subjected to uptake by the reticuloendothelial system (Figure 10A). However, 12 hours post-injection, NIR fluorescence intensity in renal and tumor tissue were increased dramatically. Figure 10B displayed the detailed semiquantitative results on biodistribution of Pluronic polymeric micelles as a function of time. The fluorescence intensity in the heart, liver, spleen, and lung decreased in a similar way. The NIR fluorescence intensity of P105/F127 micelles in tumor reached peak at 12 hours post-injection, maintained for about 12 hours and then decreased gradually. The significant tumor targeting effect of P105/F127 micelles could be interpreted by the relatively long circulation time of Pluronic mixed micelles. DIR-labeled micelles could be detectable

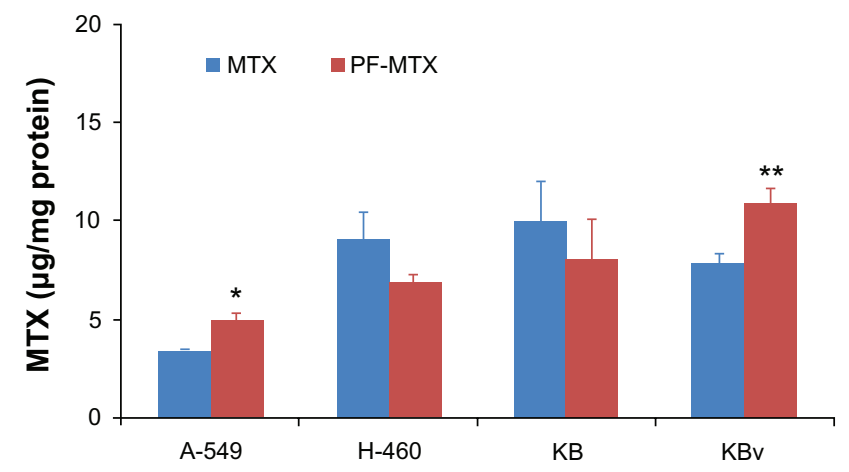

Figure 8 MTX cellular uptake of $0.5 \mu \mathrm{g} / \mathrm{mL}$ free MTX and PF-MTX after incubation for 4 hours at $37^{\circ} \mathrm{C}$ in $\mathrm{H}-460, \mathrm{~A}-549, \mathrm{~KB}$, and $\mathrm{KBv}$ cells.

Notes: Values are means \pm standard deviation $(n=3)$. $* P<0.05 ; * * P<0.01$, compared to MTX treatment.

Abbreviations: MTX, methotrexate; PF-MTX, methotrexate loaded PI05/FI27 mixed micelles.

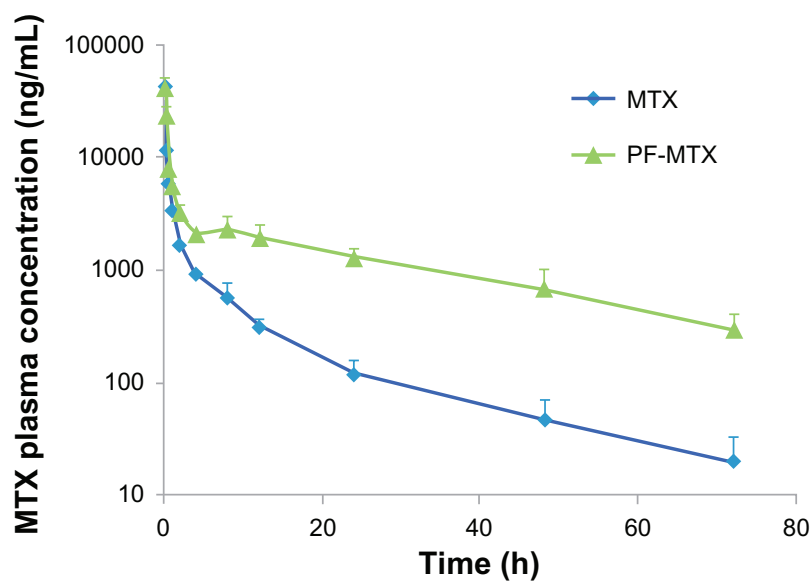

Figure 9 Plasma concentration-time curves of MTX and PF-MTX after intravenous administration to rats at the same dose of $4 \mathrm{mg} / \mathrm{kg}$ MTX.

Note: Values are means \pm standard deviation $(n=6)$.

Abbreviations: MTX, methotrexate; PF-MTX, methotrexate loaded PI05/FI27 mixed micelles.

in the blood even 48 hours post intravenous administration, indicating that P105/F127 micelles were relatively stable in the bloodstream. It is well known that tumors have a compromised endothelial barrier which facilitates molecular transport. Long-circulating nanocarriers were found to be taken up by tumor cells and macrophages. Additionally, the in vitro release kinetics of DIR-labeled P105/F127 micelles (DIR content: $0.2 \%$ ) was investigated using the dialysis method. These results indicated that only less than $1 \%$ of DIR released from the micelles within 72 hours (data not shown) suggesting that it was DIR labeled micelles penetrating into the tumor microenvironment and major organs not free DIR in the real-time NIR imaging analysis.

\section{In vivo antitumor efficacy}

In vivo anti-tumor activity of PF-MTX is shown in Figure 11A. The relative tumor volume of the PF-MTX

Table 3 Comparative pharmacokinetic parameters of MTX and PF-MTX

\begin{tabular}{lcc}
\hline Parameters & Formulations \\
\cline { 2 - 3 } & \multicolumn{1}{c}{ MTX } & \multicolumn{1}{c}{ PF-MTX } \\
\hline $\mathrm{t}_{1 / 2}(\alpha)(\mathrm{h})$ & $0.497 \pm 0.197$ & $0.294 \pm 0.162^{* *}$ \\
$\mathrm{t}_{1 / 2}(\beta)(\mathrm{h})$ & $10.031 \pm 4.091$ & $21.994 \pm 3.63^{* *}$ \\
$\mathrm{AUC}_{0 \rightarrow \mathrm{t}}(\mu \mathrm{g} / \mathrm{L} / \mathrm{h})$ & $23.452 \pm 3.205$ & $95.764 \pm 7.592^{* *}$ \\
$\mathrm{AUC}_{0 \rightarrow \infty}(\mu \mathrm{g} / \mathrm{L} / \mathrm{h})$ & $23.809 \pm 3.331$ & $107.292 \pm 8.927 * *$ \\
$\mathrm{MRT}(\mathrm{h})$ & $9.491 \pm 1.662$ & $29.616 \pm 6.039 * *$ \\
$\mathrm{CL}(\mathrm{L} / \mathrm{h} / \mathrm{Kg})$ & $0.154 \pm 0.026$ & $0.038 \pm 0.002^{*}$ \\
$\mathrm{~V}_{\mathrm{d}}(\mathrm{L} / \mathrm{Kg})$ & $0.347 \pm 0.137$ & $0.124 \pm 0.08$ \\
\hline
\end{tabular}

Notes: Values are means \pm standard deviation $(n=6)$. $* P<0.05 ; * * P<0.01$, compared to the MTX group.

Abbreviations: MTX, methotrexate; PF-MTX, methotrexate loaded PI05/FI27 mixed micelles. 


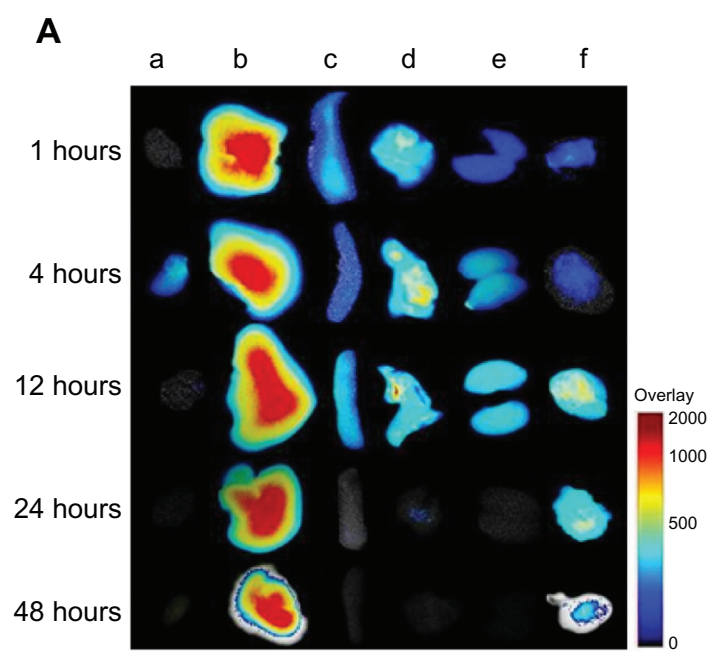

B

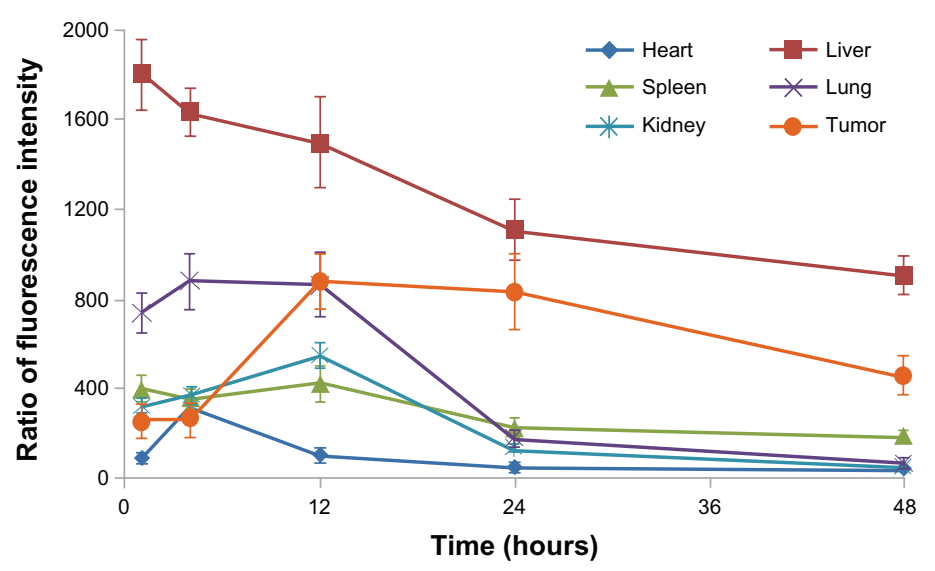

Figure 10 Representative ex vivo near infrared fluorescence images of dissected organs of KBv tumor-bearing nude mice sacrificed at I, 4, 12,24 and 48 hours after intravenous injection of DIR-labeled PI05/FI 27 mixed micelles (DIR content: 0.2\%): a, heart; b, liver; c, spleen; d, lung; e, kidney; f, tumor (A); ratio of the relative fluorescence intensity in dissected organs as a function of time after intravenous injection of DIR-labeled PI05/FI27 mixed micelles (B).

Note: Values are means \pm standard deviation $(n=3)$.

Abbreviation: DIR, dioctadecyl-3,3,3',3'-tetramethylindotricarbocyanine iodide.
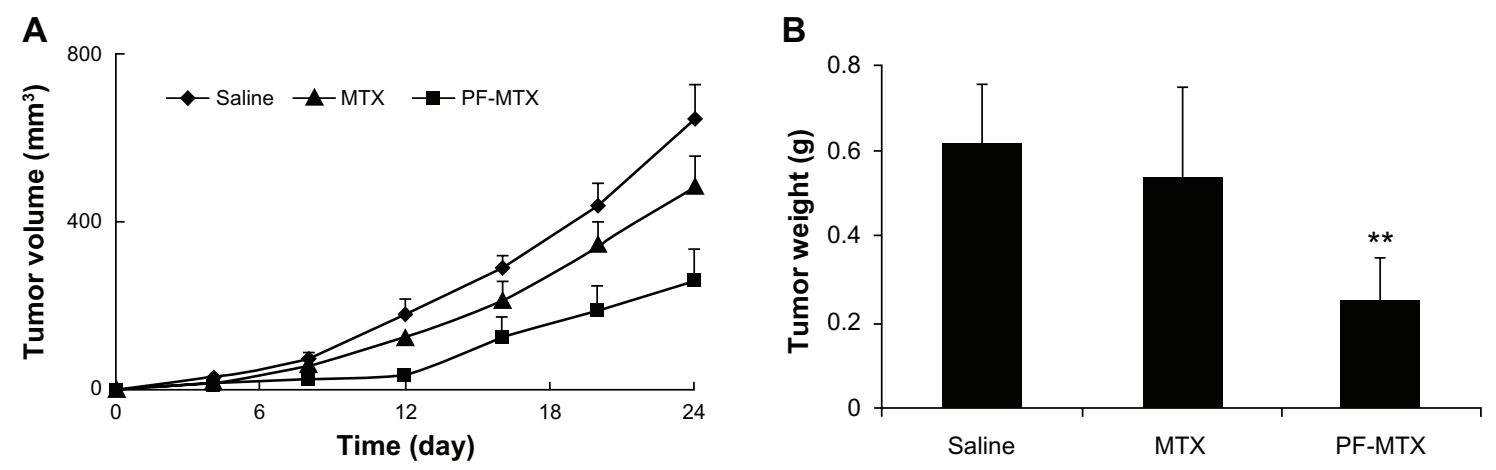

Figure II In vivo anti-tumor efficacy of PF-MTX in subcutaneous KBv tumor-bearing nude mice. Changes in tumor volumes from different MTX formulations (A); the weights of tumor mass of each treatment group at the time of sacrifice (B).

Notes: Values are means \pm standard deviation $(n=6)$; **P $<0.0$ I, compared to the MTX group.

Abbreviations: MTX, methotrexate; PF-MTX, methotrexate loaded PI05/FI 27 mixed micelles.

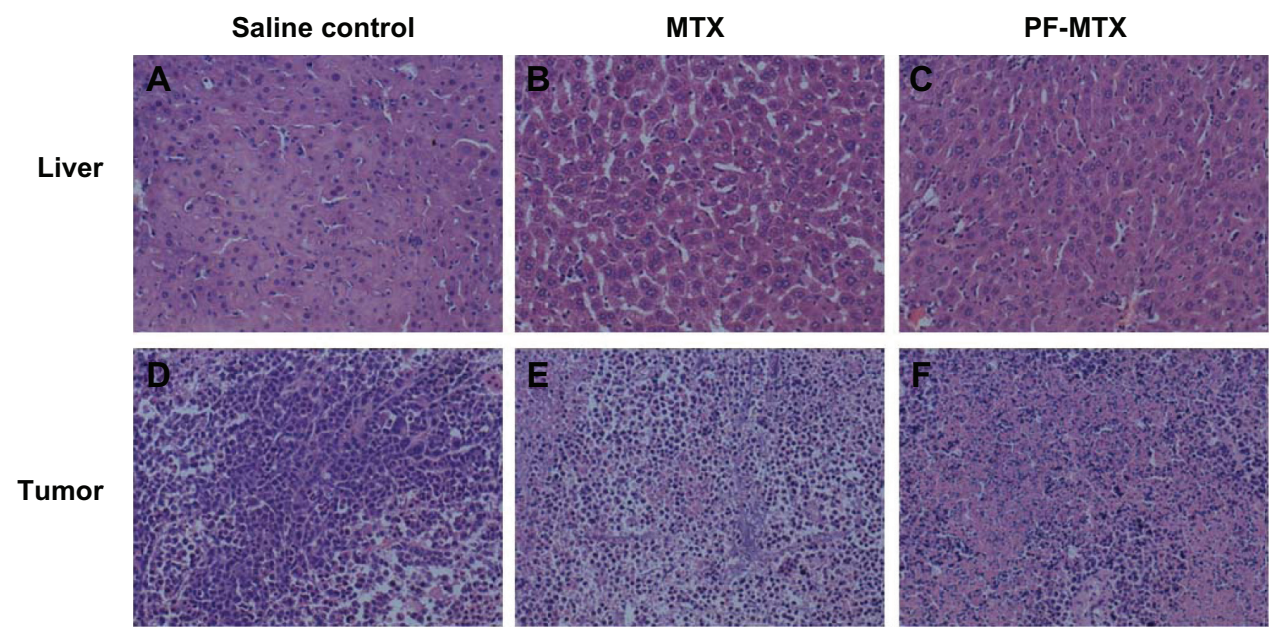

Figure 12 Hematoxylin and eosin stained liver (A-C) and tumor (D-F) sections isolated from mice 24 hours after intravenous administration of saline, 5 mg/kg MTX, and PF-MTX every four days, six continuous times.

Note: Original magnification: $\times 20$.

Abbreviations: MTX, methotrexate; PF-MTX, methotrexate loaded PI05/FI27 mixed micelles. 
group was much smaller than animals with saline and MTX injection during the whole experimental period, indicating the high anti-tumor activity of PF-MTX. In addition, the tumor mass excised from the KBv xenograft tumor bearing mice model was measured after treatments (Figure 11B). There was no significant difference in tumor weights between saline group and MTX injection group, while the tumor weight of PF-MTX group was significantly reduced compared to the control group $(P<0.01)$. The tumor inhibition rate of PF-MTX was $58.06 \%$, which was significantly higher than for MTX $(12.90 \%, P<0.01)$. Taken together, these data show that the antitumor efficacy of PF-MTX was greatly superior to that of free MTX in the KBv tumor bearing mice model. MDR is often found in many types of human tumors that have relapsed after an initial favorable response to drug therapy. So far, there are two major forms of drug resistance encountered in the clinic, one of which is acquired resistance, which occurs following continuous exposure to drugs. ${ }^{43}$ The sensitivity of tumor cells to antineoplastic agents can decrease gradually, which hinders the efficacy of these drugs in cancer therapy. ${ }^{44}$ Another form of drug resistance is known as intrinsic resistance, which is an innate property of tumor cells and is not triggered by drug exposure. MTX resistance develops through decreased folate carrier-mediated membrane transport, dihydrofolate reductase gene amplification, specific transcription-translational modifications, and down regulation of intracellular MTX polyglutamation. ${ }^{45}$ Therefore MTX has been used for treating malignancies in combination with other chemotherapeutic agents. The results of the in vivo antitumor efficacy of MTX and PFMTX were consistent with in vitro cytotoxicity and cellular uptake studies. The combined effect of chemosensitization of MDR tumors by Pluronic block copolymer and passive targeting by polymeric micelles could be the main reason for the significant suppression of tumor growth in PF-MTX group. Besides, Pluronic that interacts in mitochondria promoting the release of cytochrome $\mathrm{C}$ and accumulation of reactive oxygen species in MDR cells ${ }^{46}$ is also a likely reason for the enhanced apoptosis observed in tumor tissue in response to the drug. In addition, the excised liver and tumor tissues were sectioned and stained with H\&E to evaluate necrosis levels in the liver (Figure 12A-C) and tumor (Figure 12D-F). Qualitatively, PF-MTX showed no obvious change in histology and no necrosis, congestion, or hydropic degeneration was observed compared to the control group. Results indicated that no visible lesions were observed in liver after PF-MTX treatment. Moreover, the necrosis area in tumor tissue in the PF-MTX group was found to be the largest among the three groups (Figure 12F). In contrast, the MTX injection treated tumor tissue still had a large amount of viable tumor cells (Figure 12E) indicating that PF-MTX exhibited a greater therapeutic efficacy than MTX injection against MDR tumors.

\section{Conclusion}

PF-MTX micelles were prepared using a thin-film hydration method in this study. The optimized formulation displayed suitable particle size and distribution, high drug-loading and $\mathrm{pH}$-dependent drug release. The MTX cellular uptake in A-549 and KBv MDR cells was much higher in the PFMTX group compared to MTX. Additionally, PF-MTX displayed higher anti-tumor efficacy than free MTX in both MDR cancerous cell lines. The pharmacokinetic studies demonstrated that PF-MTX can significantly increase the blood circulation time of MTX. In vivo realtime studies also indicated passive accumulation of polymeric mixed micelles in tumor tissues. Furthermore, PF-MTX exhibited remarkable antitumor activity against KBv MDR tumor xenografts and induced less systemic toxicity in comparison with MTX injection. Taken together, PF-MTX micelles are a potential drug delivery system for MDR tumor chemotherapy.

\section{Acknowledgments}

The work was sponsored by National Natural Science Foundation of the People's Republic of China (30901862); Shanghai Rising-Star Program (10QA1400800); National Basic Research Program of the People's Republic of China (2013CB932500) and National Science and Technology Major Project (2012ZX09304004).

\section{Disclosure}

The authors report no conflicts of interest in this work.

\section{References}

1. Zhang Y, Jin T, Zhuo RX. Methotrexate-loaded biodegradable polymeric micelles: preparation, physicochemical properties and in vitro drug release. Colloids Surf B Biointerfaces. 2005;44(2-3):104-109.

2. Banerjee D, Mayer-Kuckuk P, Capiaux G, Budak-Alpdogan T, Gorlick R, Bertino JR. Novel aspects of resistance to drugs targeted to dihydrofolate reductase and thymidylate synthase. Biochim Biophys Acta. 2002;1587(2-3):164-173.

3. Lorico A, Toffoli G, Boiocchi M, et al. Accumulation of DNA strand breaks in cells exposed to methotrexate or N10-propargyl-5,8-dideazafolic acid. Cancer Res. 1988;48(8):2036-2041.

4. Thomas H, Coley HM. Overcoming multidrug resistance in cancer: an update on the clinical strategy of inhibiting p-glycoprotein. Cancer Control. 2003;10(2):159-165.

5. Berger WU, Setinek P, Hollaus, et al. Multidrug resistance markers P-glycoprotein, multidrug resistance protein 1, and lung resistance protein in non-small cell lung cancer: prognostic implications. J Cancer Res Clin Oncol. 2005;131(6):355-363. 
6. Oh JM, Park M, Kim ST, Jung JY, Kang YG, Choy JH. Efficient delivery of anticancer drug MTX through MTX-LDH nanohybrid system. J Phys Chem Solids. 2006;67:1024-1027.

7. Rahman A, Husain SR, Siddiqui J, et al. Liposome-mediated modulation of multidrug resistance in human HL-60 leukemia cells. J Natl Cancer Inst. 1992;84(24):1909-1915.

8. Booser DJ, Esteva FJ, Rivera E, et al. Phase II study of liposomal annamycin in the treatment of doxorubicin-resistant breast cancer. Cancer Chemother Pharmacol. 2002;50(1):6-8.

9. Garcion E, Lamprecht A, Heurtault B, et al. A new generation of anticancer, drug-loaded, colloidal vectors reverses multidrug resistance in glioma and reduces tumor progression in rats. Mol Cancer Ther. 2006; 5(7):1710-1722.

10. Vauthier C, Dubernet C, Chauvierre C, Brigger I, Couvreur P. Drug delivery to resistant tumors: the potential of poly(alkyl cyanoacrylate) nanoparticles. J Control Release. 2003;93(2):151-160.

11. Koziara JM, Whisman TR, Tseng MT, Mumper RJ. In-vivo efficacy of novel paclitaxel nanoparticles in paclitaxel-resistant human colorectal tumors. J Control Release. 2006;112(3):312-319.

12. Minko T, Kopecková P, Pozharov V, Kopeck J. HPMA copolymer bound adriamycin overcomes MDR1 gene encoded resistance in a human ovarian carcinoma cell line. J Control Release. 1998;54(2):223-233.

13. Minko T, Kopecková P, Kopeck J. Preliminary evaluation of caspasesdependent apoptosis signaling pathways of free and HPMA copolymer bound doxorubicin in human ovarian carcinoma cells. J Control Release. 2001;71(3):227-237.

14. Kabanov AV, Batrakova EV, Alakhov VY. Pluronic block copolymers for overcoming drug resistance in cancer. Adv Drug Deliv Rev. 2002; 54(5):759-779.

15. Batrakova EV, Kelly DL, Li S, et al. Alteration of genomic responses to doxorubicin and prevention of MDR in breast cancer cells by a polymer excipient: pluronic P85. Mol Pharm. 2006;3(2):113-123.

16. Jabr-Milance LS, Vlerken LE, Yadav S, Amiji MM. Multi-functional nanocarriers to overcome tumor drug resistance. Cancer Treat Rev. 2008;34(7):592-602.

17. Danson S, Ferry D, Alakhov VY, et al. Phase I dose escalation and pharmacokinetic study of pluronic polymer-bound doxorubicin (SP1049C) in patients with advanced cancer. Br J Cancer. 2004;90(11): 2085-2091.

18. Matsumura Y, Hamaguchi T, Ura T, et al. Phase I clinical trial and pharmacokinetic evaluation of NK911, a micelle-encapsulated doxorubicin. Br J Cancer. 2004;91(10):1775-1781.

19. Mizumura Y, Matsumura Y, Yokoyama M, et al. Incorporation of the anticancer agent KRN5500 into polymeric micelles diminishes the pulmonary toxicity. Jpn J Cancer Res. 2002;93(11):1237-1243.

20. MatsumuraY.Preclinical and clinical studies of anticancer drug-incorporated polymeric micelles. J Drug Target. 2007;15(7-8):507-517.

21. Batrakova EV, Kabanov AV. Pluronic block copolymers: evolution of drug delivery concept from inert nanocarriers to biological response modifiers. J Control Release. 2008;130(2):98-106.

22. Minko T, Batrakova EV, Li S, et al. Pluronic block copolymers alter apoptotic signal transduction of doxorubicin in drug-resistant cancer cells. J Control Release. 2005;105(3):269-278.

23. Wang YZ, Yu L, Han LM, Sha XY, Fang XL. Difunctional Pluronic copolymer micelles for paclitaxel delivery: synergistic effect of folatemediated targeting and Pluronic-mediated overcoming multidrug resistance in tumor cell lines. Int J Pharm. 2007;337(1-2):63-73.

24. Zhang W, Shi Y, Chen Y, et al. Enhanced antitumor efficacy by paclitaxel-loaded pluronic P123/F127 mixed micelles against non-small cell lung cancer based on passive tumor targeting and modulation of drug resistance. Eur J Pharm Biopharm. 2010;75(3):341-353.

25. Zhang W, Hao JG, Yuan S, et al. Paclitaxel-loaded Pluronic P123/ F127 mixed polymeric micelles: formulation, optimization and in vitro characterization. Int J Pharm. 2009;376(1-2):176-185.

26. Kim D, Lee ES, Park K, Kwon IC, Bae YH. Doxorubicin loaded pHsensitive micelles: antitumoral efficacy against ovarian A2780/DOXR tumor. Pharm Res. 2008;25(9):2074-2082.
27. Lee ES, Gao Z, Kim D, Park K, Kwon IC, Bae YH. Super pH-sensitive multifunctional polymeric micelle for tumor $\mathrm{pH}(\mathrm{e})$ specific TAT exposure and multidrug resistance. J Control Release. 2008;129(3):228-236.

28. Batrakova EV, Li S, Alakhov VY, Miller DW, Kabanov AV. Optimal structure requirements for pluronic block copolymers in modifying P-glycoprotein drug efflux transporter activity in bovine brain microvessel endothelial cells. J Pharmacol Exp Ther. 2003;304(2):845-854.

29. Wang Y, Hao J, Li Y, et al. Poly(caprolactone)-modified Pluronic P105 micelles for reversal of paclitaxcel-resistance in SKOV-3 tumors. Biomaterials. 2012;33(18):4741-4751.

30. Chaibundit C, Ricardo NM, Costa Fde M, Yeates SG, Booth C. Micellization and gelation of mixed copolymers P123 and F127 in aqueous solution. Langmuir. 2007;23(18):9229-9236.

31. Chiappetta DA, Sosnik A. Poly(ethylene oxide)-poly(propylene oxide) block copolymer micelles as drug delivery agent: improved hydrosolubility, stability and bioavailability of drugs. Eur J Pharm Biopharm. 2007;66(3):303-317.

32. Zhang W, Shi Y, Chen Y, Hao JG, Sha XY, Fang XL. The potential of Pluronic polymeric micelles encapsulated with paclitaxel for the treatment of melanoma using subcutaneous and pulmonary metastatic mice models. Biomaterials. 2011;32(25):5934-5944.

33. Hu FQ, Liu LN, Du YZ, Yuan H. Synthesis and antitumor activity of doxorubicin conjugated stearic acid-g-chitosan oligosaccharide polymeric micelles. Biomaterials. 2009;30(36):6955-6963.

34. Yang B, Guo C, Chen S, et al. Effect of acid on the aggregation of poly(ethylene xide)-poly(propylene oxide)-poly(ethylene oxide) block copolymers. J Phys Chem B. 2006;110(46):23068-23074.

35. Rapoport N, PittWG, Sun H, Nelson JL. Drug delivery in polymeric micelles: from in vitro to in vivo. J Control Release. 2003;91(1-2):85-95.

36. Swennen ELR, Ummels V, Buss I, Jaehde U, Bast A, Dagnelie PC. ATP sensitizes H460 lung carcinoma cells to cisplatin-induced apoptosis. Chem Biol Interact. 2010;184(3):338-345.

37. Meschini S, Marra M, Calcabrini A, et al. Role of the lung resistancerelated protein (LRP) in the drug sensitivity of cultured tumor cells. Toxicol in Vitro. 2002;16(4):389-398.

38. Kitazono M, Sumizawa T, Takebayashi Y, et al. Multidrug resistance and the lung resistance-related protein in human colon carcinoma SW-620 cells. J Natl Cancer Inst. 1999;91(19):1647-1653.

39. Hira A, Watanabe H, Maeda Y, et al. Role of P-glycoprotein in accumulation and cytotoxicity of amrubicin and amrubicinol in MDR1 genetransfected LLC-PK1 cells and human A549 lung adenocarcinoma cells. Biochem Pharmacol. 2008;75(4):973-980.

40. Kabanov AV, Batrakova EV, Alakhov VY. Pluronic block copolymers as novel polymer therapeutics for drug and gene delivery. J Control Release. 2002;82(2-3):189-212.

41. Ueda K, Kawaguchi Y, Iwakawa S. Effect of oxyethylene numbers on the pharmacokinetics of menatetrenone incorporated in oil-in-water lipid emulsions prepared with polyoxyethylene-polyoxypropylene block copolymers and soybean oil in rats. Biol Pharm Bull. 2008;31(12):2283-2287.

42. Park K, Kim JH, Nam YS, et al. Effect of polymer molecular weight on the tumor targeting characteristics of self-assembled glycol chitosan nanoparticles. J Control Release. 2007;122(3):305-314.

43. Banerjee D, Mayer-Kuckuk P, Capiaux G, Budak-Alpdogan T, Gorlick R, Bertino JR. Novel aspects of resistance to drugs targeted to dihydrofolate reductase and thymidylate synthase. Biochim Biophys Acta. 2002;1587(2-3):164-173.

44. Alakhov VYU, Moskaleva EYU, Batrakova EV, Kabanov AV. Hypersensitization of multidrug resistant human ovarian carcinoma cells by pluronic P85 block copolymer. Bioconjug Chem. 1996;7(2):209-216.

45. Lindgren M, Rosenthal-Aizman K, Saar K, et al. Overcoming methotrexate resistance in breast cancer tumour cells by the use of a new cell-penetrating peptide. Biochem Pharmacol. 2006;71(4): 416-425.

46. Batrakova EV, Li S, Brynskikh AM, et al. Effects of pluronic and doxorubicin on drug uptake, cellular metabolism, apoptosis and tumor inhibition in animal models of MDR cancers. J Control Release. 2010; 143(3):290-301. 


\section{Publish your work in this journal}

The International Journal of Nanomedicine is an international, peerreviewed journal focusing on the application of nanotechnology in diagnostics, therapeutics, and drug delivery systems throughout the biomedical field. This journal is indexed on PubMed Central, MedLine, CAS, SciSearch $\AA$, Current Contents ${ }^{\circledR} /$ Clinical Medicine,
Journal Citation Reports/Science Edition, EMBase, Scopus and the Elsevier Bibliographic databases. The manuscript management system is completely online and includes a very quick and fair peer-review system, which is all easy to use. Visit http://www.dovepress.com/ testimonials.php to read real quotes from published authors.

Submit your manuscript here: http://www.dovepress.com/international-journal-of-nanomedicine-journal 